\title{
Intellectual development in Apert's syndrome: a long term follow up of 29 patients
}

\author{
M A PATTON, J GOODShIP, R HAYWARD, AND R LANSDOWN \\ From the Hospitals for Sick Children, Great Ormond Street, London WCIN 3JH.
}

SUMmARY Twenty-nine patients with Apert's syndrome were ascertained through hospital records. The mean age was $19 \cdot 3$ years (range eight to 35 years). Further information was obtained on their intelligence, education, and employment records. Fourteen patients (48\%) had a normal or borderline IQ $(>70)$, nine patients $(31 \%)$ were mildly mentally retarded (IQ 50 to 70 ), four patients (14\%) were moderately retarded (IQ 35 to 49 ), and two patients (7\%) were severely retarded (IQ <35). Early craniectomy did not appear to improve intellectual outcome. Six of the seven school leavers with normal or borderline intelligence were in full time employment or vocational training.

Apert's syndrome is the most widely recognised craniosynostosis syndrome. It was first described by Wheaton ${ }^{1}$ in 1894 and subsequently further cases were reported by Apert ${ }^{2}$ in 1906 . It consists of an irregular craniosynostosis associated with a tall, brachycephalic skull, midfacial hypoplasia, reduced supraorbital ridges, and a beak shaped nose. The palate is narrow and often cleft. The syndactyly in the hand usually involves the second, third, fourth, and fifth fingers leading to a mitten shaped appearance, and the syndactyly in the foot usually involves all the toes. A variety of visceral abnormalities has also been reported. ${ }^{3}$

Mental retardation may be present, but the incidence of mental impairment and prognosis for intellectual development has not been clearly defined. Blank ${ }^{3}$ reported 39 cases of Apert's syndrome in a comprehensive survey of patients in the United Kingdom in 1960 and concluded that "some mental impairment, not necessarily amounting to imbecility, was judged to be present in almost every case". Cohen ${ }^{4}$ reported mental deficiency in three out of 10 cases. David et $a l^{5}$ found three out of five patients tested were of dull average intelligence and the remaining were mentally retarded.

Above average intelligence (IQ 110) was reported by Bertelsen' in a patient who had incorrectly been assigned to a mental handicap hospital.

In order to obtain a clearer view of mental development and the long term natural history of this syndrome, we have carried out a follow up study

Received for publication 19 December 1986.

Revised version accepted for publication 19 February 1987 in 29 patients between the ages of eight and 35 years. All patients had been assessed formally or informally by a clinical psychologist. Information on education, and in the older subjects employment, was also collected.

\section{Patients and methods}

The patients for this study were ascertained from the medical records at The Hospitals for Sick Children, Great Ormond Street, London between the years 1952 and 1980. The hospital is a major referral centre and receives patients from all parts of the United Kingdom. Patients born after 1980 were not included in the study as their educational abilities had not been fully assessed. Thirty-six patients were ascertained from the search. All had mitten shaped syndactyly of the fingers and syndactyly of the toes together with craniosynostosis and a characteristic facial appearance. Other craniosynostoses with polysyndactyly, irregular syndactyly, or atypical facial appearance were excluded. Four had died in the first year of life and were therefore excluded from the study. Three had insufficient information in the hospital notes and were therefore also excluded.

The 29 patients in the study had ages ranging from eight to 35 years (mean age 19.3 years). The age distribution is illustrated in the figure. There were 17 females and 12 males.

Information on IQ testing, schooling, deafness, and visual handicap was obtained from the hospital notes. In order to obtain more recent information about schooling and employment, the patient's

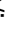




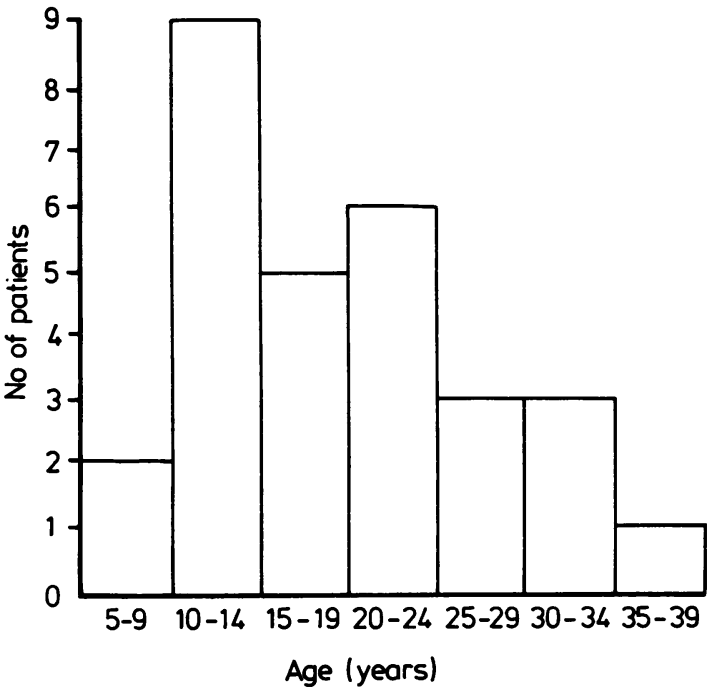

FIGURE Age distribution of 29 patients in the study.

general practitioner and parents were contacted as appropriate. In 25 cases the patient's general practitioner was contacted and in 13 cases this was followed up by a postal questionnaire to the parents. In eight instances parents volunteered more information listing special skills and problems that their children had encountered.

All the patients in the study had been assessed by the clinical psychologist in the Department of Psychological Medicine as part of the protocol for patients referred to the craniofacial clinic. In 19 patients there was a formal quantitative assessment of IQ and in 10 cases the psychologist had made an informal assessment.

\section{Results}

The IQ distribution of the 29 patients with Apert's syndrome is shown in table 1 . Fourteen $(48 \%)$ had a normal or borderline IQ and $15(52 \%)$ were mentally retarded.

The classification of mental handicap was that given by the World Health Organization. ${ }^{7}$ For the

TABL.E 1 IQ distribution.

\begin{tabular}{lll}
\hline & No & Sex \\
\hline Borderline/normal IO $(>7(1)$ & $14(48 \%)$ & $4 \mathrm{M}$, IOF \\
Mild mental retardation $(50-7(1)$ & $9(31 \%)$ & $3 \mathrm{M}$. 6F \\
Moderate mental retardation $(35-49)$ & $4(14 \%)$ & $4 \mathrm{M}$ \\
Severe mentat retardation $(<35)$ & $2(7 \%)$ & $2 \mathrm{M}$ \\
\hline
\end{tabular}

purposes of this study the borderline and normal IQs were grouped together, as some children were assessed by psychologists as 'average' or 'low average' intelligence. No child who had a formal assessment had an IQ greater than 100 .

The relationship between cranial surgery and intelligence is shown in table 2 . All children with craniectomies had had the procedure performed in the first year of life. The Tessier procedure was performed later, around the time of puberty. There was no significant difference in the proportion of patients with craniectomies in the retarded and nonretarded groups $\left(\chi^{2}=0 \cdot 24\right.$, NS).

A survey of the educational placement of the 29 patients showed that the 15 retarded patients all went to special schools, although one child had been placed in a school for the deaf rather than a school for the educationally subnormal (table 3 ). Of the 14 children with borderline or normal IQ, nine went to normal schools, while five went to special schools. The five who attended special schools included one at a school for the physically handicapped and one at a school for the visually handicapped. Three of the seven school leavers with normal or borderline IQs have obtained CSE examinations. Their results were three, four, and seven passes respectively.

The outcome for patients with Apert's syndrome after leaving school was also looked at (table 4). Seven of the 14 school leavers were of normal or borderline IQ and had found suitable training or employment. Four were in full time employment and were financially self sufficient. They had found posts as a clerical worker, petrol attendant, storekeeper, and a care assistant in a Church hostel. Two had recently left school and were undertaking

TABLE: 2 The relationship between cranial surgery and intelligence.

\begin{tabular}{lll}
\hline & Re'tarded & Not retarded \\
\hline Cranicctomy & 5 & 7 \\
Cranicctomy and Tessier procedure & 2 & 0 \\
Tessier procedurc & 4 & 4 \\
No cranial surgery & 6 & 3 \\
\hline
\end{tabular}

TABLE: 3 Educational placement.

\begin{tabular}{l}
\hline Retarded $(1.5) \quad N o t$ returded (If) \\
\hline $\begin{array}{l}\text { Special school } \\
\text { Normal school }\end{array}$ \\
\hline *Includes one at school for deaf. \\
†Includes one at school for physically handicapped and one at school for \\
visually handicapped. \\
$\ddagger$ Three school leavers had passed CSE cxams (threc, four, and seven passes).
\end{tabular}


TABLE 4 School leavers 18 years or over.

\begin{tabular}{lll}
\hline Normal/borderline IQ & No & Comment \\
& 7 & $\begin{array}{c}4 \text { in full time employment (microfilming, petrol attendant, } \\
\text { storekeeper, and care assistant); } 2 \text { in further education } \\
\text { (catering course, school leaver's work experience); } 1 \text { in } \\
\text { sheltered workshop. }\end{array}$ \\
$\begin{array}{l}\text { Mild mental retardation } \\
\begin{array}{l}\text { Moderate retardation } \\
\text { Severe mental retardation }\end{array}\end{array}$ & 3 & 2 \\
\hline
\end{tabular}

vocational training. Finally, one was employed in a sheltered workshop and would have been unable to find employment in the open market. None of those with IQs of 70 or less had found employment, but most lead reasonably independent lives. Only one patient required long term custodial care in a hospital for the mentally handicapped and his retardation was partly due to severe birth asphyxia.

Associated handicaps did not significantly impair their schooling or employment. Seventeen of the 29 patients $(58 \%)$ had had conductive deafness, but this was usually improved by grommets. Nine of the 29 patients $(31 \%)$ had had a cleft palate and had received adequate surgery and speech therapy. Three of the patients $(10 \%)$ had significant visual problems but in only one case had this interfered with education. All patients had syndactyly of the fingers and had received plastic surgery for this. With appropriate treatment this did not present a major handicap to the children, as was shown by the number of school leavers who were proficient typists. In the questionnaires returned by parents a number of special skills were reported. Four patients could type, four had learnt to drive a car, two had a special interest in computing, and four had learnt to swim.

\section{Discussion}

Apert's syndrome is a rare disorder estimated to occur in one in every 160000 births $^{3}$ and therefore most studies have depended on relatively small numbers. In our study we initially ascertained 36 patients from the 18 year period. As most of these patients were referred to the hospital for craniofacial surgery, there might be a bias towards those with greatest cosmetic disfigurement, but there should be no specific bias towards those who were developmentally delayed.

The study showed that $52 \%$ of patients with Apert's syndrome had an IQ below 70. Severe mental retardation was rare and in one of the two cases with severe retardation, birth asphyxia was almost certainly a contributory cause. An IQ greater than 70 (borderline or normal IQ) was present in
$48 \%$. In this group it was not possible to define further the range of IQs, as some of the assessments were made qualitatively by a clinical psychologist. None of the patients was assessed as having an IQ above the normal range.

The children followed in this study entered their education before the Education Act 1981 took effect. This is reflected in the fact that three of the patients who were not retarded were sent to schools for the educationally subnormal.

One of these three was a notable example of misplacement. She was a girl who had been abandoned by her family because of her physical deformities and spent the first seven years of her life in a residential home for the mentally handicapped. After the staff of the home noted that she had greater abilities than her contemporaries she was formally tested by a psychologist, found to have an IQ in the normal range, and was placed in state education. She subsequently left school with four CSE passes and is taking a vocational training course in catering.

A useful measure of the quality of life with a particular handicap is the ability to find a satisfactory job and be financially independent. Seven of the school leavers had IQs greater than 70 and, of these, four were in full time employment and two were on vocational training courses. This level of employment, particularly in the presence of widespread youth unemployment, is very satisfactory. In terms of employment, the special skills that some or patients reported are of special note. The ability to type in particular has contributed to the employ- $\sigma$ ment prospects.

It is impossible from this study to draw any firm N conclusions on the life expectancy of Apert's syn- $\sigma$ drome. However, four of the 36 patients originally ascertained died as infants (at four months, two months, five months, and 10 months). One further patient died aged 27 years from asphyxia during status epilepticus.

The cause of mental retardation in Apert's $\overrightarrow{\mathbb{D}}$ syndrome is unclear. One possibility is that prema- $\frac{?}{\mathbb{Q}}$ ture closure of the cranial sutures limits brain $\varrho$ growth and hence intelligence. However, the rela- 
tionship between cranial surgery and intelligence suggests that this is not the case. If premature closure of the sutures is to be prevented, then early craniectomy is required, but this did not appear to have reduced the proportion of retarded patients in this study. The Tessier procedure was carried out in the early teens, when brain maturation is largely complete and thus would not be expected to improve intelligence.

Another possible cause of mental retardation is hydrocephalus. Hogan and Bauman ${ }^{8}$ reported six cases of Apert's syndrome with varying degrees of hydrocephalus and suggested ventricular shunting could reduce the severity of mental retardation. None of the patients in the study had hydrocephalus but, unfortunately, because we had chosen to look at an older group of patients, most had not had CT brain scans. The final possibility is that there might be a primary abnormality in neuronal development. There have been relatively few neuropathological reports in Apert's syndrome. Crome" described the necropsy findings of neuronal paucity in the neocortex and hippocampus in a macroscopically normal brain from a patient with Apert's syndrome. One patient died during our study, but detailed neuropathology was not performed.

The results of this study provide information which will be of help in counselling families who have a child with Apert's syndrome. They also provide a baseline from which to assess new methods of treatment.
We would like to acknowledge the help we have received from the families and their general practitioners in collecting the information, and we thank Mrs Melanie Barham for her secretarial help.

\section{References}

' Wheaton SW. Two specimens of congenital cranial deformity in infants associated with fusion of the fingers and toes. Trans Pathol Soc London 1894;45:238-9.

2 Apert E. L'acrocephalosyndactylie. Bull Soc Med 1906;23: 1310-13.

${ }^{3}$ Blank CE. Apert's syndrome (a type of acrocephalosyndactyly): observations on a British series of thirty-nine cases. Ann Hum Genet 1960;24:151-64.

4 Cohen MM. Craniosynostosis and syndromes with craniosynostosis: incidence, genetics, penetrance, variability and new syndrome updating. Birth Defects 1979;XV(5B):13-63.

5 David DJ, Poswillo D, Simpson D. The craniosynostoses. Berlin: Springer Verlag, 1982.

${ }^{6}$ Bertelsen TI. The premature synostosis of the cranial sutures. Acta Ophthalmol 1958;51:1-176.

7 World Health Organization. International classification of impairments, disabilities and handicaps. Geneva: WHO, 1980.

${ }^{8}$ Hogan GR, Bauman ML. Hydrocephalus in Apert's syndrome. J Pediatr 1971;79:782-7.

${ }^{9}$ Crome L. A critique of current views on acrocephaly and related conditions. J Ment Sci 1961:107:459-74.

Correspondence and requests for reprints to $\mathrm{Dr}$ Michael Patton, Department of Child Health, St George's Hospital Medical School, Cranmer Terrace, London SW17 0RE. 